\title{
STRUCTURING JUDICIAL DISCRETION IN CHINA: EXPLORING THE 2014 SENTENCING GUIDELINES
}

\begin{abstract}
In recent years, a range of western jurisdictions has introduced reforms designed to restrict and guide judicial discretion at sentencing. The reforms enacted include mandatory sentencing laws and guiding statutes prescribing sentencing purposes and principles as well as important aggravating and mitigating factors. However, formal guidelines are the most promising and well-studied innovation. We may now add China to the growing list of countries that have recognized the utility of guidelines. Over the past decade, China has slowly developed sentencing guidelines for its courts. The new guidelines contain both general directions with respect to the determination of sentence as well as specific numerical guidelines for common offences. The guidelines do not follow the approach taken by the US schemes, many of which employ a two-dimensional sentencing grid. Instead, China has adopted a strategy consisting of "Starting Point" sentences which are then adjusted by the court to reflect relevant mitigating and aggravating factors. This approach is much closer to the guidelines developed in England and Wales and those proposed but not yet implemented in New Zealand and Israel. In this article, we explore the new Chinese guidelines and provide a limited comparative analysis with guidelines in other jurisdictions. England and Wales is selected as the principal comparator since it has developed and implemented a comprehensive system consisting of both offence-specified guidelines as well as generic guidelines.
\end{abstract}

\section{INTRODUCTION}

In recent years, many jurisdictions have introduced reforms designed to restrict and guide judicial discretion at sentencing. ${ }^{1}$ The reforms enacted include mandatory sentencing laws and guiding statutes pre-

* Professor, University of Oxford, E-mail: julian.roberts@worc.ox.ac.uk.

** Respectively, the Faculty of Law, University of Oxford and the Erasmus China Law Centre, Erasmus School of Law, Erasmus University of Rotterdam. We thank Gabrielle Watson for her meticulous research assistance.

${ }^{1}$ See Ch 6, A. von Hirsch, A. Ashworth and J.V. Roberts (eds), Principled Sentencing (Oxford: Hart Publishing, 3rd edn, 2009). 
scribing sentencing purposes and principles as well as important aggravating and mitigating factors. However, formal guidelines are the most promising and well-studied innovation. Minnesota was the first jurisdiction to implement detailed sentencing guidelines for courts. ${ }^{2} \mathrm{At}$ sentencing in that (and other states), courts must follow the guideline sentence ranges or find "substantial and compelling" reasons to depart therefrom. Since the creation of the Minnesota Sentencing Guidelines Commission in 1975, many other US states have adopted comparable schemes. In addition, advisory or statutorily binding guidelines have been implemented or proposed in a range of other jurisdictions, including England and Wales, Scotland, South Korea, Israel and, most recently, Uganda. ${ }^{3}$ To the growing list of countries that have recognized the utility of guidelines, we may now add China.

Over the past decade, China has slowly developed sentencing guidelines for its courts. In 2014, after ten years' development, the Supreme Peoples' Court (SPC) issued its "Sentencing Guidelines for Common Crimes" (hereafter "Guidelines"): the first set of comprehensive, national guidelines in the jurisdiction. ${ }^{4}$ The new guidelines contain both general directions with respect to the determination of sentence as well as specific numerical guidelines for 15 common offences. The guidelines do not follow the approach taken by the US schemes, many of which employ a two-dimensional sentencing grid..$^{5}$ Instead, China has adopted a strategy consisting of "Starting Point" sentences which are then adjusted by the court to reflect relevant mitigating and aggravating factors. This approach is much closer to the guidelines developed in England and Wales and those proposed but not yet implemented in New Zealand and Israel. ${ }^{6}$

\footnotetext{
${ }^{2}$ See R. Frase, 'Sentencing Guidelines in Minnesota, 1978-2003', in M Tonry (ed), Crime and Justice: A Review of Research (Chicago: University of Chicago Press, 2005).

${ }^{3}$ For information on these jurisdictions, see, respectively, A. Ashworth and J.V. Roberts, Sentencing Guidelines: Exploring the English Model (Oxford: Oxford University Press, 2013); H. Park, 'The Basic Features of the First Korean Sentencing Guidelines', (2010) 22 Federal Sentencing Reporter 262-271; J. Kamuzze, 'An Insight into Uganda's New Sentencing Guidelines: A Replica of Individualisation?', (2014) 27(1) Federal Sentencing Reporter 47-55.

4 关于常见犯罪的量刑指导意见; 法发[2013] 14号 (Fafa [2013] No. 14) (issued 23 December 2013, validated 1 January 2014), at: http://en.pkulaw.cn/display.aspx? cgid $=221534 \&$ lib $=$ law.

${ }^{5}$ For example, in Minnesota, see discussion in R Frase (n 2 above).

${ }^{6}$ Information on the New Zealand experience can be found in W. Young and A. King, 'The Origins and Evolution of Sentencing Guidelines: A Comparison of England and Wales and New Zealand', in A. Ashworth and J.V. Roberts (n 3 above); for the sentencing law of Israel and discussion of the Israeli experience, see $\mathbf{J}$.
} 
In this article, we explore the new Chinese guidelines and provide a limited comparative analysis with other jurisdictions. Part II summarizes recent sentencing trends regarding the use of custody and notes the historical origins, evolution and legal framework of the 2014 Guidelines in China. This is followed in Part III by a comparison between the Chinese and English sentencing guidelines. England and Wales is selected as the principal comparator since it has developed and implemented a comprehensive system consisting of both offence-specified guidelines as well as generic guidelines. ${ }^{7}$ We compare the institutional features, principles and sentencing methodologies in the two jurisdictions. Part IV discusses the compliance requirements in the two jurisdictions. Some challenges regarding the 2014 Guidelines are discussed in part V.

\section{RECENT SENTENCING TRENDS AND ORIGINS OF THE 2014 GUIDELINES}

\subsection{Use of Custody as a Sanction}

Most sentencing guidelines focus on the use of custody, often with a view to constraining rising prison populations or to ensure that only the most serious cases are committed to prison. Indeed, an increasing prison population is often a trigger for the introduction of statutorilybinding guidelines. It is unclear whether this problem played a role in launching the Chinese guidelines, but it is apparent that China employs imprisonment as a sanction more frequently than most common law countries, with the exception of the United States. The imprisonment rate in most western jurisdictions is around 100 per 100,000 population, with the US recording a rate significantly higher. Data released by the International Centre for Prison Studies (ICPS) reveal that as of mid-2013, China had a rate of 124 per 100,000 population. ${ }^{8}$ In terms of the use of custody relative to other sanctions, China also stands out. In England and Wales, approximately

\section{Footnote 6 continued}

V. Roberts and O. Gazal-Ayal, 'Sentencing Reform in Israel: An Analysis of the Statutory Reforms of 2012', (2013) 46 Israel Law Review 455-479.

${ }^{7}$ For analysis of the sentencing guidelines in England and Wales, see A. Ashworth and J.V. Roberts (n 3 above) and J.V. Roberts, 'Sentencing Guidelines in England and Wales: Recent Developments and Emerging Issues', (2013) 76 Law and Contemporary Problems 1-25.

\footnotetext{
${ }^{8}$ See the ICPS World Prison Brief, at: http://www.prisonstudies.org/country/china.
} 
$10 \%$ of convictions in 2013 resulted in a term of immediate custody. ${ }^{9}$ In contrast, over half the convictions in China the same year resulted in a term of imprisonment. The custodial population has also risen significantly in recent years; in less than a decade (2001-2010) the prison population rose by $16 \% .^{10}$

\subsection{Origins of the New Guidelines}

In 1979, China began to reform its criminal justice system by promulgating a new criminal law $(1979 \mathrm{CL})^{11}$ and Criminal Procedure Law (1979 CPL). ${ }^{12}$ These two statutes form the basis of the current regulatory framework on judicial decision-making. As is the practice in almost all other civil law jurisdictions, Chinese judges are bound by the written law in which the constituents of criminal activities and sanctions and the concepts of seriousness and culpability are defined. The previous sentencing regime suffered from a number of deficiencies. First, the statutory sentencing ranges were very broad, allowing for a great deal of judicial discretion. For example, the sentence range for "normal" robbery ran from three to ten years' imprisonment. The sentence range for cases of robbery with aggravating factors rose from ten years' imprisonment up to the death penalty, and judges had great discretion to sentence within these broad outer limits. At the same time, the scheme lacked a comprehensive methodology to guide trial judges in the exercise of their discretion.

The first defect was somewhat mitigated by judicial interpretations of the CPL. Since 1979, the head of the judicial system in China including both the Supreme Peoples' Court (SPC) and the Supreme People's Procurate (SPP) ${ }^{13}$ - has issued 67 detailed interpretations. These interpretations are not based on specific cases but are closer to practice memoranda issued by appellate courts in other jurisdictions.

\footnotetext{
${ }^{9}$ See J.V. Roberts and K. Irwin-Rogers, 'Sentencing Practices and Trends in England and Wales, 1999-2013', in J.V. Roberts (ed), Exploring Sentencing Practice in England and Wales (London: Palgrave Macmillan, 2015).

${ }^{10}$ SPC statistics on trial court trends which are available from the authors.

${ }^{11}$ The 1979 CL was revised in 1997 (1997 CL) and has been amended eight times since then. The draft of Amendment IX was released on 3 November 2014. .

12 The 1979 CPL was revised in 1996 (1996 CPL) and then in 2012 (2012 CPL).

${ }^{13}$ This is different from the English system where the 'judicial system' refers to the judiciary rather than the Crown Prosecution Service. In China, both peoples' courts ('normal' courts) and the procurates (the public prosecution service) are deemed branches of the judicial system and there is a close degree of cooperation between the two.
} 
Their function is limited to refining the terms used in specific crimes such as the meaning of "public transportation" or the range of "large sums of money" in the definition of robbery. Little guidance was provided to assist judges in weighing relevant sentencing factors (such as whether the offender had confessed, pleaded guilty, or performed meritorious service). ${ }^{14}$

The second defect is the absence of a systematic methodology for the determination of sentences. Absent such a system, individual judges are likely to approach the determination of sentence and the application of relevant factors in very different ways. One of the major consequences is likely to be a disparity in sentencing outcomes. In the absence of a comprehensive sentencing database (such as those found in western jurisdictions), it is hard to determine the degree of sentencing disparity in trial courts. For this reason, it is necessary to rely upon specific reported cases. A typical example is the Xu Ting (许霆) case. In 2006, Xu took advantage of a malfunctioning ATM machine in Guangdong Province to illegally withdraw more than 170,000 RMB (approximately \$US 25,000). In the trial of first instance in 2007, the defendant was convicted of stealing cash from a financial institution. This is an aggravated form of theft and the offender was sentenced to life imprisonment. Although within the range prescribed by law, the sentence provoked adverse public reaction; the public considered the punishment to be excessively severe. ${ }^{15}$ Under the pressure of public opinion, the sentence was subsequently reduced to five years' imprisonment in $2008 .{ }^{16}$ Prior to Xu's case, He Peng (何鹏), convicted of a similar offence (withdrawing 429,700 RMB (\$US 69, 826) in Yun'nan Province), had also been sentenced to life imprisonment in 2002. After the commutation in $\mathrm{Xu}$ Ting's case, in 2009 the SPC required the Higher Peoples' Court in

\footnotetext{
${ }^{14}$ The term 'Meritorious service' has a specific connotation in this context. It refers to cases where criminal suspects/defendants offer assistance to investigators or prosecutors, rather than more nonspecific exemplary conduct by the defendant.

${ }^{15}$ For the media intervention in the Xu case and commentary, see e.g., L. Bo, 'The Trial of Xu Ting' The Economic Observer Online (14 April 2008), at: http://www. eeo.com.cn/ens/feature/2008/04/23/97760.html.

${ }^{16}$ For details of the Xu Ting Case, see Z Yuan, 'Xu Ting and the Era of Judicial Discretion' China Daily (10 August 2008), at: http://www.chinadaily.com.cn/cndy/ 2008-05/10/content_6674712.htm.
} 
Yun'nan Province to order a retrial in He Peng's case, and in the same year, He's penalty was reduced to eight years' imprisonment. ${ }^{17}$

These two cases are examples of the perceived inconsistency in sentencing practices across China, as well as the low levels of public confidence in the administration of criminal justice and, in particular, sentencing. Recognition of these problems, as well as the need to achieve consistency and transparency in sentencing practices across the country led to a judicial response. In 2004, the SPC announced its intention to improve sentencing through guidelines in the Second Five-Year Reform Program for the Peoples' Court (2004-2008). ${ }^{18}$ Then, in 2008, the SPC promoted the harmonization of sentencing in 12 local peoples' courts (basic and intermediate levels). ${ }^{19}$ Two years later, draft guidelines were issued, expanding the experiment to peoples' courts across the country. In 2013, the SPC revised the draft guidelines (2014 Guidelines) and required all peoples' courts to stipulate detailed regulations and implement them before the end of 2014. Considering the variable legal, political and economic developments across the country as well as localized legal cultures and traditions, the Opinions also require detailed guidelines to be issued in accordance with local conditions. To date, 29 higher peoples' courts have issued (or updated) detailed instructions on implementing the 2014 Guidelines ${ }^{20}$. The following discussion focuses on the official guidelines issued at the central level.

The position of the 2014 Guidelines in the sentencing system in China needs some explanation. In China the SPC is regarded as a body that actually has a "quasi-lawmaking function". By issuing different forms of documents, the SPC instructs lower courts on how to implement the national criminal policy. These documents mainly take four forms: regulations (guiding, including opinions and stan-

${ }^{17}$ For details of the He Peng Case, see L. Yingqing and G. Anfei, "ATM "Thief" wants compensation' China Daily (19 January 2010), at: http://www.chinadaily. com.cn/china/2010-01/19/content_9339444.htm.

18 第二个人民法院改革五年计划， at: http://www.cecc.gov/resources/legalprovisions/second-five-year-reform-program-for-the-peoples-courts-2004-2008-cecc.

19 The structure of Chinese courts for normal criminal cases consists of four levels: the basic peoples' courts, the intermediate peoples' courts, the higher peoples' courts and the SPC. All four levels can hold first instance trials in accordance with the seriousness of the crime. For an introduction to Chinese criminal procedure, see M. McConville, Criminal Justice in China: An Empirical Inquiry (Cheltenham and Northampton: Edward Elgar, 2011).

${ }^{20}$ The only courts in mainland China which have not issued or updated their implementation instructions are Neimenggu and Xinjiang. 
dards), interpretations (jieshi), decisions (jueding), and replies (pifu). They are generally named "judicial interpretations" and "semi-judicial interpretations", bound by the 1997 CL and having national binding force. Documents directly named "interpretations" can be used as legal basis in verdicts.

\subsection{Structure of the Chinese Guidelines}

The 2014 Chinese Guidelines contain four principal elements: (1) general sentencing principles; (2) a methodology for the determination of sentence; (3) enumerated sentencing factors; and (4) specific guidelines for 15 common offences or offence categories, including traffic offences, assault, rape, illegal confinement, robbery, theft, fraud, forcible seizure, embezzlement, extortion, obstructing an officer in the discharge of his duties, affray, causing a disturbance, concealing the illegal gains or the income from illegal gains, and the smuggling, selling, or manufacturing of prohibited drugs. The 2014 Guidelines are the first stage of a more comprehensive national sentencing scheme. They focus on the two forms ${ }^{21}$ of imprisonment available to Chinese courts yet provide no guidance regarding noncustodial penalties. ${ }^{22}$ In this respect, they fail to attain the breadth of coverage achieved in the US and England and Wales, where guidelines provide assistance to courts over the range of principal sanctions, including fines, community orders as well as sentences of imprisonment.

\section{2014 GUIDELINES IN COMPARISON: STRUCTURE, OBJECTIVES AND METHOD}

\subsection{Structural Features}

Several important structural differences exist between the Chinese and English sentencing regimes. First, instead of establishing an independent sentencing authority such as the Sentencing Council (SC) for England and Wales, guidelines and related reforms in China are promoted by and located within the SPC, the highest level of the judiciary. The Chinese guidelines are therefore purely judicially-de-

${ }^{21}$ Offenders may be sentenced to either imprisonment or "criminal detention".

${ }^{22}$ As with other jurisdictions, Chinese courts may impose a range of penalties (in addition to the two forms of imprisonment) including the death penalty, life imprisonment, deprivation of political rights, fines, and confiscation of property. The 2014 Guidelines apply only to the two forms of definite terms of custody. 
rived, without input from non-judicial members or external bodies. In contrast, the English Council, and indeed all sentencing councils and commissions around the common law world, include non-judicial members. Membership of the English Council includes several other legal and criminal justice professionals as well as an academic. Sentencing councils in Australia contain victim representatives as well as practitioners and community members. ${ }^{23}$

This is an important distinction which has been much discussed in the academic literature. It has been argued that a sentencing guidelines authority which lacks community or practitioner membership and is exclusively or predominantly judicial - will be more conservative in its guidelines, and more protective of the status quo in terms of sentencing practices. ${ }^{24}$ The claim has also been made that the presence of community members confers a degree of legitimacy which would otherwise be absent: the guidelines in England and Wales and Australia reflect community values to a greater degree than, for example, the exclusively judicial guidelines developed in Uganda. ${ }^{25}$

On the other hand, a purely judicial sentencing authority is likely to attract greater support from the judiciary. Guidelines emerging from a primarily judicial body are more likely to conform to a judicial model of guidance and more consequently more likely to attract judicial support. Indeed, one explanation for the emergence of guidelines in England and Wales when they have been rejected in other countries is that the English judges have been more accepting of the Council since it is predominantly composed of members of the judiciary. ${ }^{26}$

${ }^{23}$ See discussion in A. Freiberg and K. Gelb (eds), Penal Populism, Sentencing Councils and Sentencing Policy (Cullompton: Willan Publishing/Federation Press, 2008).

${ }^{24}$ See M. Tonry and S. Rex, 'Reconsidering sentencing and punishment in England and Wales', in S. Rex and M. Tonry (eds), Reform and Punishment (Willan: Cullompton, 2002).

${ }^{25}$ For discussion of these issues, see contributions in A. Freiberg and K. Gelb (n 23 above).

${ }^{26}$ Without this characteristic, the guidelines may not attract sufficient support from the judiciary. This was the case in Canada in the 1980s, when a Sentencing Commission failed in part because of judicial opposition. See discussion in J.V. Roberts and H. Bebbington, 'Sentencing Reform in Canada: Promoting a Return to Principles and Evidence-Based Policy', (2013) 17(3) Canadian Criminal Law Review 327-347. 


\subsubsection{Offence-Specific Guidelines}

Another important difference between the English and Chinese guidelines is that the English sentencing guidelines follow an offencespecific structure. Each category of offence (e.g. assault, drugs, and sexual offences) has its own definitive guideline containing offencespecific sentence ranges associated with different levels of seriousness. In China, general sentencing principles as well as guidance with respect to specific crimes are located in a single document. The categories of crime and levels of seriousness in the Chinese guidelines are regulated by the $1997 \mathrm{CL}$ and relevant judicial interpretations in China. This structure requires that before referring to the guidelines, a Chinese sentencer should employ criminal codes to identify the elements of an offence with a view to establishing its relative seriousness. This distinction is to some extent due to the role of sentencing guidelines in the overall sentencing system. In China, the 2014 Guidelines are located within the hierarchical structure of statutes on sentencing. They are directed and restricted by the sentencing ranges prescribed in the $1997 \mathrm{CL}$, its amendments and relevant interpretations. The English guidelines, by contrast, exist alongside guideline judgments from the Court of Appeal. The two sources of guidance interact; the Council develops guidelines consistent with existing appellate jurisprudence, and the Court of Appeal often provides additional context and clarification for the guidelines in its judgments.

\subsection{Principles and Objectives}

The first article of the Guidelines identifies four objectives:

(1) structuring discretion at sentencing;

(2) implementing a policy of tempering justice with mercy;

(3) enhancing the transparency of sentencing; and

(4) promoting justice in sentencing.

The last objective is an overarching objective, achieved through fulfilling the former three. The subsequent question is: what kind of sentencing can be considered 'just'? From the other three objectives, it seems to include the following requirements: that judicial discretion is properly exercised, that the sanctions are appropriately balanced in terms of the severity/leniency dimension and that the sentencing process is transparent. Transparency is a key objective of the Chinese guidelines: to make the sentencing process comprehensible to other participants of the procedure as well as the general public. If this objective is achieved, it is likely to assist the accused to defend his 
case, enhance public confidence in the judiciary, and to help individual judges and local courts to resist extra-judicial interference. For instance, when confronted with adverse public reaction to a specific sentence, the court can point to the national guidelines to support its decision. ${ }^{27}$

Further exploration is needed to clarify the first two objectives. Whether the discretionary power is properly deployed depends on the purpose and principles of sentencing in China, which are clearly described in the $1997 \mathrm{CL}$. Two main purposes are acknowledged in the Criminal Law: (i) the punishment of offenders and (ii) the protection of society. Crime prevention and punishment are of course the twin pillars of sentencing around the world. Most sentencing statutes recognize the utilitarian (preventive) objectives of deterrence, rehabilitation and incapacitation as well as the retributive (just deserts) approach which recognizes the central role of proportional punishment. China's sentencing regime therefore conforms to this dual approach to sentencing.

Another important common element is the primordial sentencing principle of proportionality. The key principle of sentencing in China under the $1997 \mathrm{CL}$ is to promote proportionality between the severity of sanctions and the seriousness of the offence for which sentence is imposed. This explicit acknowledgement of the proportionality principle is consistent with statutory sentencing schemes throughout the common law world. For example, s 718.1 of the Criminal Code of Canada identifies proportionality as being the "fundamental" principle guiding sentencers - one that assumes greater importance than other principles - and section 8(a) of the Sentencing Act 2002 in New Zealand contains a similar provision.

As to the second objective of implementing the policy of tempering justice with mercy, it echoes the latest changes with respect to the state strategies in China regarding crime control. The policy was first proposed by Luo Gan, former Secretary of the Central Politics and Law Commission of China Communist Party, at the national working conference of politics and law on 5 December 2005. Before that, the dominant policy emphasized severity in crime control, especially by means of "Severe Strike Campaigns" (SSC). The SSC is a special strategy employed by the Chinese government in combating

${ }^{27}$ B. Ahl, 'Retaining Judicial Professionalism: The New Guiding Cases Mechanism of the Supreme Peoples' Court', (2014) 217 China Quarterly 121-139. 
crime. It involves the imposition of summary, severe policies and often the approaches adopted are far beyond rule of law. ${ }^{28}$

However, the failure of this punitive approach over the past three decades $^{29}$ and concerns over violations of the rule of law and infringements of human rights have precipitated government reform. ${ }^{30}$ According to the SPC's interpretations in $2010,{ }^{31}$ "tempering justice with mercy" requires the judicial system to distinguish crimes according to their relative seriousness and to impose correspondingly proportionate sanctions. Crimes that seriously threaten the state (such as terrorism, or offences such as homicide and rape, drugrelated crimes, and high-level corruption) should be punished with severity. In contrast, offenders committing minor crimes such as those arising from civil disputes, or with considerable personal mitigation, should attract more lenient punishments.

Three other purposes are identified in the guidelines: preventing crime; achieving parity in sentencing; and promoting a correspondence between the legal and social effects of sentencing. ${ }^{32}$ The first two purposes are also found in the English sentencing regime as well as statutes in other countries. But what does "correspondence between legal and social effect" mean? This purpose is in fact an interpretation of "tempering justice with mercy" in sentencing. It reflects the reality that, on occasion, court verdicts - although issued

${ }^{28}$ The first national SSC was launched in 1983. After that, there were another three national SSC in 1996, 2001 and 2010. The former two were jointly initiated by the SPP, SPC and the Ministry of Public Security (MPS). In 2010, however, the SPP and SPC withdrew from the campaign launched by the MPS. For discussion on SSC in China and its effect on criminal justice, see e.g. S. Trevaskes, Policing Serious Crime in China: From 'Strike Hard' to 'Kill Fewer' (Oxon: Routledge, 2010); S. Trevaskes, 'Severe and Swift Justice in China', (2007) 47(1) British Journal of Criminology 23-41; B. Liang, 'Severe Strike Campaign in Transitional China', (2005) 33 Journal of Criminal Justice: 387-399; H.M. Tanner, Strike Hard! Anti-Crime Campaigns and Chinese Criminal Justice 1979-1985 (New York: Cornell University East Asian Program, 1999).

${ }^{29}$ The annual SPP annual reports reveal that every SSC was followed by a surge in criminal cases in the following years. Reports are available at: http://www.spp.gov. $\mathrm{cn} / \mathrm{gzbg} /$.

${ }^{30} \mathrm{~S}$. Trevaskes, 'The Shifting sands of Punishment in China in the era of "Harmonious Society"' (2010) 32(3) Law and Policy 332-361.

31 最高人民法院关于贯彻宽严相济刑事政策的若干意见 ('The SPC's Several Opinions on Implementing the Criminal Policy of Tempering Justice with Mercy'), 法发[2010] 9号 (Fafa [2010] No. 9), (issued and validated 8 February 2010), at: http://news.xinhuanet.com/legal/2010-02/10/content_12960937.htm.

32 法律效果与社会效果相统一. 
in accordance with law - are not accepted by the public. Such a phenomenon has frequently caused social unrest, especially in the form of constant petitioning to higher government officials. ${ }^{33}$

In England and Wales, the definitive sentencing guidelines "play an essential role" to "ensure that courts across England and Wales are consistent in their approach to sentencing". ${ }^{34}$ The function of the English guidelines is to promote greater consistency. The effect of the guidelines is expected to be internal: they focus on consistency of approach rather than outcome. This does not mean that the English system pays less attention to the outcomes of sentencing. According to the Criminal Justice Act 2003, sentencing in England and Wales is supposed to reflect one (or more) of five purposes: (1) the punishment of offenders; (2) the reduction of crime; (3) the reform and rehabilitation of offenders; (4) the protection of the public; and (5) the making of reparation by offenders to persons affected by their offences. ${ }^{35}$ These purposes are bound by the overarching principle of proportionality in sentencing. ${ }^{36}$

\subsection{The Guidelines Methodology: Determining Sentence}

Unlike the US schemes, many of which impose a two-dimensional grid upon courts, both the Chinese and English guidelines employ a stepby-step methodology to regulate sentencing. The Chinese Guidelines identify three principal steps involved in reaching a sentencing decision. Step One requires the court to identify the starting point sentence based on the essential elements of the offence. This corresponds to the first step of the English Guidelines where a court considers the "principal factual elements" of the offence. Given that the $1997 \mathrm{CL}$ prescribes categories for most crimes, the first step requires judges to

${ }^{33}$ For analysis of the phenomenon of petition in China and its impact on the formal legal system, see C.F. Minzner, 'Xinfang: An Alternative to Formal Chinese Legal Institutions', (2006) 42 Stanford Journal of International Law 103-179; CF Minzer, 'Riots and Cover-ups: Counterproductive Control of Local Agents in China', (2009) 31 University of Pennsylvania Journal of International Law 53-123; T Zhang, 'The Xinfang Phenomenon: Why the Chinese Prefer Administrative Petitioning over Litigation', (2008) 68 Student Scholarship Papers, at: http:// digitalcommons.law.yale.edu/student_papers/68.

34 'Sentencing Guidelines', at: http://sentencingcouncil.judiciary.gov.uk/sentenc ing-guidelines.htm.

${ }^{35}$ S 142(1) of Criminal Justice Act 2003.

${ }^{36}$ SGC, Overarching Principles: Seriousness, at: https://www.sentencingcouncil. org.uk/wp-content/uploads/web_seriousness_guideline.pdf. 
evaluate whether an act is crime and also which category of seriousness is appropriate. Chinese criminal procedure does not distinguish stages between conviction and sentencing; therefore Step One is also a process of conviction. Here we use robbery as an example. ${ }^{37}$

Robbery is defined under Article 263 of the 1997 CL which specifies a minimum sentence of three years' imprisonment and a maximum of the death penalty; these sentences constitute the outer limits of the sentence range. The broad offence of robbery is divided two categories of seriousness: 'conventional' and 'aggravated' robbery, with corresponding sentencing ranges for each category. For conventional robbery, the sentencing range under the $1997 \mathrm{CL}$ is from three years' to ten years' imprisonment. With respect to the starting point in sentencing, the 2014 Guidelines further recognizes two sub-ranges, depending upon the offender's prior convictions. In the absence of prior convictions for robbery, the offender is liable for a sentence with a starting point no less than three and no more than six years' imprisonment. If the offender has prior robbery convictions, the starting point of the sentence range increases to no less than six, and no more than ten years' custody.

Aggravated robbery is defined as a robbery that contains one or more aggravating features enumerated in the 2014 Guidelines, including no less than three prior robberies; causing death or serious injury; simulating a police officer during the commission of the offence; using firearms to commit the crime or robbery against a military target; or theft from emergency relief supplies. In such cases, judges can impose any term between 10 and 13 years imprisonment as the starting point and the sentencing range would be between 10 and 15 years' imprisonment. ${ }^{38}$ If the potential sentence is higher than 15 years, the 2014 Guidelines no longer apply. Sentencing above the 15 year limit is therefore comparable to sentencing outside the guideline ranges in England and Wales.

Step Two of the guidelines methodology requires a court to set the "base" sentence by considering a range of factors that affect the constituent parts of a crime. The Guidelines do not enumerate these

${ }^{37}$ The principal provision for robbery in the $1997 \mathrm{CL}$ is Article 263. Relevant interpretation is 最高人民法院关于审理抢劫、抢夺刑事案件适用法律若干问题的 意见 ('SPC's Opinions on Several Issues Concerning Applying Law in Solving Robbery and Forcible Seizure'), 法发[2005] 第8号 (Fafa [2005] No. 8), (issued and validated 8 June 2005) (hereinafter 2005 SPC Opinions).

${ }^{38}$ According to the $1997 \mathrm{CL}$, the highest level of imprisonment with a fixed-term is 15 years. In cases where multiple crimes have been committed, the highest level can be raised to 25 years. 
factors but offer examples - such as the amount of money involved, the number of counts and the extent and nature of the offence's consequences. These factors aggravate rather than mitigate the sentence compared to the starting point identified in Step One.

Step Three of the Guidelines requires judges to adjust the sentence by enhancing or reducing the baseline after considering factors unrelated to the criminal act but relevant to the offender's level of culpability. The 2014 Guidelines list 14 such sentencing factors, including ten mitigating factors and four aggravating factors (see Appendix 1). ${ }^{39}$ In this essay we shall not comment on all the factors but rather highlight the most important. First, however, we comment on the question of whether guidelines can offer guidance in terms of the quantum of aggravation or mitigation arising from the presence of various sentencing factors.

\subsubsection{Assigning Weights to Sentencing Factors}

All jurisdictions or sentencing guidelines authority grapple with the question of whether guidance should be provided on the quantum of punishment that should be increased or decreased to reflect different sentencing factors. Most schemes do not provide this level of detailed guidance, reflecting a view that it is not possible, a priori, to determine that a specific factor - say, remorse - should reduce the severity of a sentence by a specified level. Indeed, it may not even be possible to state categorically that a given factor always aggravates or always mitigates sentence. ${ }^{40}$ In the English Guidelines, for example, with one exception, relevant mitigating and aggravating factors are simply listed in the definitive guidelines. The decision as to how much weight each factor should carry is left to the discretion of individual sentencers. (The one exception is the reduction for a guilty plea. A separate, generic guideline (applicable across all cases) specifies particular levels of reduction, depending upon the timing of the plea. ${ }^{41}$ )

\footnotetext{
${ }^{39}$ See Part III of the 2014 Guidelines, Appendix 1.

${ }^{40}$ Intoxication is a good example. Under the English guidelines, committing the offence while intoxicated is an aggravating factor; however, a common plea in mitigation is that the offence was out of character and only committed because the offender had allowed himself to become excessively intoxicated. See discussion in $\mathrm{N}$ Padfield, 'Intoxication as a sentencing factor: mitigation or aggravation?', in J.V. Roberts, Mitigation and Aggravation at Sentencing (Cambridge: Cambridge University Press, 2011).

${ }^{41}$ Defendants entering a plea at the first reasonable opportunity are normally awarded a reduction of one third. The magnitude of the reduction declines the later the plea is entered, with pleas on the day of trial resulting in a reduction of $10 \%$. See
} 
The Chinese guidelines, however, break with this tradition and provide clear numerical guidance regarding the degree to which specific factors should affect the sentence. The Guidelines provide a percentage-based sentencing range for each factor. For example, if the offender pleads guilty, the judge may reduce the sentence by a maximum of $10 \%$.

\subsubsection{Principle of Totality - Sentencing in Multiple Conviction Cases} Having arrived at a provisional sentence and before reaching a final disposition, judges are required to apply the "Totality" principle in situations where the offender has been convicted of multiple crimes. This is a principle stipulated in Articles 69 and 70 of the $1997 \mathrm{CL}$ and, in another departure from guidelines in other jurisdictions, the law provides instructions on the method of calculating sentences. ${ }^{42}$ Elsewhere, guidance for multiple offence cases assumes the form of a rather vague statutory provision - for example, in the case of Canada and other common law nations. The one exception is England and Wales, where the Sentencing Council has issued a guideline on the application of the Totality principle. However, even here, the guidance is 'light touch' in the degree to which it restricts judicial discretion. The guideline offers only general advice with respect to the critical decision as to whether multiple sentences ought to be served consecutively or concurrently. ${ }^{43}$

\subsubsection{Summary}

Two conclusions may be drawn regarding the selection of sentencing factors in China. First, the guidelines show a striking sensitivity to actions by the defendant which mitigate harm or reduce sentence severity- well after the commission of the crime. The guidelines identify a constellation of actions by the defendant which may result in a more lenient disposition. Thus the expression of remorse, restitution of property, and compensation are all identified as grounds for

Footnote 41 continued

Sentencing Council, Sentence Reductions for a Guilty Plea. Definitive Guideline (London: Sentencing Council, 2007).

${ }^{42}$ According to the $1997 \mathrm{CL}$, if an offender is convicted of multiple crimes, except where he is sentenced to death or life imprisonment, the term of sentence shall be less than the total term for all the crimes but more than the term for any of the crimes. However, the term of control cannot exceed three years, the term of criminal detention cannot exceed one year and fixed-term imprisonment cannot exceed 25 years.

${ }^{43}$ Sentencing Council Guideline on Totality, at: http://www.sentencingcouncil. org.uk/wp-content/uploads/Definitive_guideline_TICs_totality_Final_web.pdf. 
mitigating sentence. Second, the relevance and importance of youthfulness for sentencing is clearly recognized. All jurisdictions have created separate sentencing regimes with greatly mitigated sentence ranges for juvenile offenders. The Chinese guidelines helpfully go further than many other jurisdictions in that they identify the justifications for imposing mitigated punishments on juveniles, viz, that young offenders' diminished capacity to understand the wrongfulness of criminal behaviour. In addition, the guidelines create two mitigated ranges of sentence length based on the defendant's age. Consistent with arrangements in England and Wales, for young offenders between 14 and 16, the sentence length imposed should be reduced from the adult rate by between $30 \%$ and $60 \%$ while for older juveniles, namely those between 16 and 18, the reduction should be more modest.

\subsubsection{The Role of Previous Convictions}

After the seriousness of the crime, prior convictions represent the most important determinant of sentence; this observation holds true in both common and civil law jurisdictions. ${ }^{44}$ The magnitude of aggravation arising from an offender's previous convictions varies widely. Across the US, criminal history exercises great influence over the sentence imposed, and in some State guidelines prior convictions carry more weight than the offence of conviction. Elsewhere, in England and Wales for example, prior convictions play a more modest role. Under the English guidelines, previous convictions are constrained by the progressive loss of mitigation, and although repeat offenders receive harsher punishments than first-time offenders, the aggravation attenuates after several convictions have been recorded. ${ }^{45}$

The Chinese guidelines affirm the relevance of previous convictions and also provide guidance as to the quantum of aggravation that should be imposed. However, a rather different approach is adopted. The Guidelines provision relating to previous convictions needs to be read in light of rules found in the 1997 law. Three categories of recidivism are distinguished. First, there is a category of repeat offender for whom the penalty should normally be aggravated: if the prior crime resulted in a term of imprisonment; if the new crime

\footnotetext{
${ }^{44}$ See discussion in J.V. Roberts, Punishing Persistent Offenders (Oxford: Oxford University Press, 2008).

45 J.V. Roberts and J. Pina-Sanchez, 'Previous Convictions at Sentencing: Exploring Empirical Trends in the Crown Court', (2014) 8 Criminal Law Review 575588.
} 
was committed within five years of the expiry of the previous sentence; and if the sentence currently imposed involves a term of custody.

The second category of offender consists of those who have previously committed an offence against state security and have now been reconvicted of a subsequent offence of this nature. There is no five-year limit on this category of offender. Finally, there is a third category of recidivists who do not fulfill the conditions of the previous, more serious categories of recidivism. Offenders in the first two categories should normally receive sentences between $10 \%$ and $40 \%$ higher as a result of their previous convictions. Offenders in the third category are subject to a much smaller $(10 \%)$ recidivist sentencing enhancement, but the court has more discretion as to whether this additional punishment will be imposed.

The guidelines are not sensitive to the relationship between the prior and current conviction, and this distinguishes them from guidelines and statutory law in other jurisdictions. For example, a number of US schemes weight prior, related offending more heavily, and offenders convicted of the same offence on multiple occasions play a higher price for their prior offending than offenders with prior unrelated offences. ${ }^{46}$ Another difference is the magnitude of the Chinese recidivist enhancements, which are more modest than those imposed in other jurisdictions.

Most offenders will be affected by s. 12 which creates a cap of $10 \%$ on the degree to which the base sentence length may be imposed. The relatively small (in international comparative terms) increment for repeat identical offending and the very low ceiling on the recidivist sentencing premium for the remaining offenders with prior crimes is another way that the Chinese Guidelines promote proportional sentencing. If an offender-related factor such as prior record plays a very important role, offense-based proportionality is threatened, and the drafters of the Chinese guidelines are sensitive to this threat. The impact of the offender's prior adjudications is further limited by the fact that the guidelines in China do not count crimes of negligence or any juvenile convictions. In the US, both these categories of prior delinquency count at the sentencing of adult offenders.

${ }^{46}$ J.V. Roberts, 'Paying for the Past: The Role of Criminal Record in the Sentencing Process', in M. Tonry (ed.), Crime and Justice: A Review of Research - Volume 22 (Chicago: University of Chicago Press, 1997). R. Frase et al., Criminal History Enhancements: A Sourcebook (Minneapolis: Faculty of Law, University of Minnesota, 2015). 
Finally, one other anomaly in the Chinese Guidelines is that previous convictions are used only as an aggravating factor and this is a departure from common practice in other jurisdictions. All common and civil law jurisdictions recognize that first offenders are less blameworthy than recidivists and impose mitigated punishments accordingly. ${ }^{47}$ Indeed, the so-called "first offender discount" is one of the most powerful sources of mitigation at sentencing. It is surprising, therefore, that the absence of priors is not considered as a mitigating circumstance under the Chinese guidelines.

\subsubsection{Rewarding Defendants for Co-operation with the Criminal Justice System}

The focus on encouraging offender co-operation with the administration of justice is consistent with other developments in Chinese law. In recent years, there has been a tendency to encourage various types of post-charge cooperation from offenders. For instance, Amendment VIII of the 1997 Criminal Law (1997 CL), which was issued in 2011, acknowledged a confession as a relevant factor for judicial consideration; the revision of the 1996 CPL in 2012 (2012 CPL) reformed summary procedure to facilitate guilty pleas; and the 2012 CPL also recognizes reconciliation as a special procedure to encourage victim-offender agreement. In addition, providing information to investigators or assisting in the prosecution of other defendants has long been recognized as a mitigating factor in China under the heading "meritorious service" ${ }^{48}$ Furthermore, criminal reconciliation between offenders and victims has been recognized by the 2012 CPL. $^{49}$

Post-offence cooperation recognized in the 2014 Opinions can be categorized into three types: admission of guilt, meritorious service, and reconciliation with victims. Admission of guilt includes three categories and the 2014 Guidelines prescribe different maximum sentence reductions for each: $40 \%$ for voluntary surrender before the

\footnotetext{
${ }^{47}$ J.V. Roberts, Punishing Persistent Offenders: Community and Offender Perspectives on the Recidivist Sentencing Premium (Oxford: Oxford University Press, 2008); J. V. Roberts and A. von Hirsch (eds), Previous Convictions at Sentencing: Theoretical and Applied Perspectives (Oxford: Hart Publishing, 2010).

${ }^{48}$ Article 68 of the 1997 CL.

49 Article 277 of the 2012 CPL regulates victim-offender reconciliation in (1) intentional crimes with a possible sanction of at most three years' imprisonment; or (2) negligent crimes with a possible sanction of at most seven years' imprisonment.
} 
crime is detected, ${ }^{50} 20 \%$ for confession at the pre-trial stage, ${ }^{51}$ and $10 \%$ for entering guilty plea in court.

The meritorious service category distinguishes 'normal' service and more contributions. The key distinctions between them are (1) whether or not the crime carries a possible sentence of no less than lifetime imprisonment, or (2) whether or not the crime had a great impact at either the provincial or the national level. ${ }^{52}$ The maximum discounts for meritorious service range from $20 \%$ to $50 \%$, and a total exemption is possible in exceptional cases. ${ }^{53}$ Regarding victims, the 2014 Guidelines distinguish four forms: (1) criminal reconciliation under Article 277 of the 2012 CPL; (2) the offender makes compensation and obtains the victim's forgiveness, but the offence of conviction does not fall into the scope of criminal reconciliation; (3) the offender makes compensation but the victim refuses to forgive; and (4) the offender fails to provide compensation but still obtains the victim's forgiveness. The corresponding discounts for these four situations range from $20 \%$ to $50 \%$.

The levels of credits in three categories reflect several objectives. For admissions of guilt, the purpose is to encourage early cooperation, and therefore the general rule is the earlier the plea, the higher the discount - an arrangement which corresponds to plea-based sentence reductions in England and Wales, as well as other western jurisdictions. In the case of meritorious service, the main purpose is to facilitate the investigation, prosecution and conviction of other criminal suspects, and therefore the general principle is that the more valuable the assistance in solving other crimes, the higher the discount. As to reconciliation with victims, both financial compensation and the victim's forgiveness are emphasized as two primary objectives.

${ }^{50}$ Voluntary surrender regarding minor crimes may qualify the offender for more than $40 \%$ sentencing discount or even a total exemption, see Section 4 of the 2014 Guidelines.

${ }^{51}$ Confession of crimes of the same type as the conviction but of a higher seriousness can get the offender up to $30 \%$ sentencing discount and confessions that prevent extremely serious consequences can attract reductions of up to $50 \%$. Section 6 of the 2014 Opinions.

52 最高人民法院关于处理自首和立功具体应用法律若干问题的解释 ('The SPC Interpretations on Several Legal Issues on the Application of Voluntary Surrender and Meritorious Performance'), 法释[1998] 8号 (Fashi [1998] No. 8) (issued and validated 9 May 1998), at: http://www.law-lib.com/law/law_view.asp?id=13925.

53 Section 5 of the 2014 Opinions. 
To conclude, both the English and Chinese guidelines encourage courts to follow a systematic methodology at sentencing. The English guidelines require courts to work through nine steps ${ }^{54}$ : (1) determine the category of seriousness of the case; (2) shape the provisional sentence to reflect relevant mitigating and aggravating factors, some of which are specified in the guidelines; (3) reduce the sentence to reflect any assistance the offender provided to the State; (4) reduce the sentence to reflect a guilty plea; (5) consider application of the dangerousness criteria, if relevant; (6) apply the totality principle, if relevant; (7) consider imposing a compensation order or other orders; (8) give reasons for the sentence; (9) award credit for any time spent on remand or bail. ${ }^{55}$ The first six steps are also found in the Chinese Guidelines. As the 2014 Guidelines apply only to imprisonment and criminal detention, other penalties relevant to step seven in the English Guidelines are not included. As to step nine, the recognition of pre-trial detention or supervision is explicitly encapsulated in the 1997 CL in China and it is not within judges' discretion.

The principal distinction between the English and Chinese guidelines is found at Step Eight of the former which requires courts to give reasons for their sentencing decisions. Since this step is crucial in examining judges' compliance with the sentencing guidelines and has special importance for offenders and other stakeholders, the compliance issue is examined separately in the next section of this paper.

\section{REQUIREMENT FOR COURTS TO COMPLY WITH GUIDELINES AND TO EXPLAIN SENTENCE}

A key issue to be resolved in the construction of guidelines is the degree of constraint that is imposed upon courts. Although as noted, in Minnesota the guidelines are presumptively binding on courts, in some other US jurisdictions, guidelines are merely advisory. As with other regulations issued by the SPC, the 2014 Guidelines are binding upon all courts across the country. This is consistent with guideline schemes in other jurisdictions such as England and Wales where the compliance requirement has recently been strengthened. The Cor-

\footnotetext{
${ }^{54}$ Although the Council's first definitive guideline (for assault offences) adopts a nine-step methodology, some more recent guidelines issued by the Council have used a different approach (for examples and explanation, see the Sentencing Council website, at: http://www.sentencingcouncil.org.uk).

55 J.V. Roberts (n 7 above).
} 
oners and Justice Act 2009 (CJA 2009) amended the term "have regard to" in the previous statute (the Criminal Justice Act 2003 (CJA 2003)) to "should follow" and this stricter compliance requirement is binding upon the magistrates' courts and the Crown court. ${ }^{56}$

Unlike their English counterparts, however, Chinese judges are not obliged to give reasons or to explain, for the benefit of the offender, the effect and consequences of the sentence. Before 2010, most verdicts were unavailable to the public in China, a state of affairs that can only impede public understanding of sentencing. In that year, the SPC began to publish courts' verdicts online although it was not implemented on a national level until the end of 2013, when the SPC promulgated Regulations on Publishing Verdicts of Peoples' Courts Online. ${ }^{57}$ According to this document, verdicts of peoples' courts on every level should be published online except for those (1) involving state secrets or individual privacy; (2) involving juveniles; (3) resolved through mediation; and (4) other "improper" situations (Article 4). The new scheme provided an opportunity to explore judges' reasoning and decision-making processes as well as their compliance with the 2014 Guidelines. However, some deficiencies in sentencing judgments are clear. To illustrate these defects, we refer to a recent judgment. $^{58}$

In this case, the court recorded a conviction of intentional injury against Wang. The offender was interrogated by the police as a result of his suspicious behaviour. He confessed and subsequently pleaded guilty in court, decisions which can result in a more lenient punishment. Wang played a lesser role in the offence and this justifies additional leniency. According to section 1 of Article 234, section 1 of Article 25 and section 1 of Article 67 of the 1997 CL and Article 1 of the SPC Interpretations on Several Issues in Applying Law on Dealing with Voluntary Surrender and Meritorious Service, ${ }^{59}$ the court sentenced him to ten months' imprisonment.

\footnotetext{
${ }^{56}$ For discussion on the evolution of the requirement on compliance in English sentencing guidelines, see J.V. Roberts, 'Sentencing Guidelines and Judicial Discretion', (2011) 51 British Journal of Criminology 997-1013.

57 人民法院在互联网公布裁判文书的规定, 法释[2013] 26号 (Fashi [2013] No. 26) (issued 21 November 2013, validated 1 January 2014), at: http://www.court.gov.cn/ qwfb/sfjs/201311/t20131129_189898.htm. According to these Regulations, verdicts must be published on the official website Judicial Opinions of China, at: http://www. court.gov.cn/zgcpwsw/.

58 (2014) 鄂汉阳未刑初字(Ehanyangweixingchuzi) No. 00034.

59 法释[1998] 8号 (Fashi [1998] No. 8) (issued and validated 9 May 1998).
} 
The judgment in this case has several defects. First, it summarises facts rather than providing a thorough exegesis of the court's reasoning. The peoples' court's arguments on conviction and sentence are normally compressed into one paragraph after the summary of case facts and evidence. There is no way of determining whether the court followed the guidelines' recommended ranges of increase or the reductions for various sentencing factors. Second, aggravating factors and mitigating factors are simply noted; there is no indication provided of their impact upon the sentence imposed. Third, verdicts do not identify the starting point and baseline for the court's calculations. Sometimes the credit for specific factors can be inferred from the appellate judgment, where the original sentence is modified. For instance, in Li X case in 2013, the sentence was reduced from three years' imprisonment to two years and nine months' imprisonment - a reduction of approximately $10 \%$ - in recognition of the defendant's voluntary surrender. ${ }^{60}$ This is, however, still far from the maximum $40 \%$ prescribed in SPC's sentencing guidelines, and no reasons are provided to explain the starting point, the baseline, and the factors considered by a court when it awarded credit for voluntary surrender.

In comparison, since courts must give reasons for departing from the guidelines, it is easier to examine the relationship between judicial decisions and sentencing guidelines in England and Wales, with a view to determining whether a court has discharged its statutory duty to "follow any relevant guideline". Judgments issued since the creation of the definitive guidelines more often provide a detailed calculus of the factors affecting the nature and quantum of punishment imposed. ${ }^{61}$ The more detailed judgments found in the Crown court in England and Wales also facilitate appellate review. For example, if a court notes that the offender was awarded a one-quarter sentence length reduction for having entered a guilty plea, the Court of Appeal can compare this to the prescribed guideline recommendation, and intervene if necessary. Appellate review is likely to be far more challenging in China.

\footnotetext{
${ }^{60}$ See (2013) 二中刑终字(Erzhongxingzhongzi) No. 1987, 2nd Intermediate Peoples' Court in Beijing.

${ }^{61}$ See e.g. $R$ v Kiely [2009] EWCA Crim para 756.
} 


\section{CONCLUSION}

Although it is too early to determine the effects of the 2014 Guidelines, some challenges are clear, the principal of which is how to monitor departures and evaluate the impact of the guidelines in the absence of any sentencing data. Although the Chinese guidelines aim to enhance public confidence and resist extra-judicial interference in sentencing, the sentencing process still remains opaque in individual cases, as little additional information can be gleaned from the judgments. In light of this, it seems unlikely that public skepticism and cynicism about sentencing will be mitigated by the new Guidelines, at least as long as those statutory directions are not reflected in specific, publicly-available judgments.

Second, although both the Anglo-Welsh and Chinese guidelines employ starting point sentences and sentencing ranges for different categories of seriousness, in China, the former also refer to a range rather than a specific number. Chinese judges have to determine their own starting point sentences. This element of the guidelines is consistent with the approach adopted by the Sentencing Reform Act in Israel. ${ }^{62}$ As a result of that statute, courts in Israel have to develop their own starting point and sentence ranges, unlike the English or US-based guidelines which provide this information to the court.

The third challenge is the significant degree of judicial discretion that remains under the new guidelines. For example, for the offence of robbery, the guidelines only help judges to locate the starting point more accurately and do little to restrict the effective range of sentence. Even if an offender falls into the first range (with a starting point between three and six years' imprisonment), the final sentence can still be as high as ten years' custody. This is due to the fact that the current interpretations have not specified and classified the situations within a certain range. As judicial interpretations, the 2014 Guidelines can only prescribe detailed sentencing ranges based on existing regulations rather than inventing new criminal codes.

The fourth challenge to the 2014 Guidelines in China concerns the dispersed regulations on sentencing. The guidelines are merely part of the relevant sentencing rules, and their effect cannot be guaranteed without being coordinated with criminal codes and judgments. Again, we cite robbery as an example. The 2014 Guidelines are not applicable to offenders who are liable to life imprisonment or the

\footnotetext{
${ }^{62}$ For text of the sentencing law and commentary thereon, see V. Roberts and O. Gazal-Ayal (n 6 above).
} 
death penalty. Nevertheless, the second range of robbery encompasses sentencing from ten years' imprisonment to capital punishment, and there are no specific rules on the exercise of discretion between these limits. In other words, the cases described in the guidelines for normal imprisonment may also result in much more severe sanctions. At present, the longest period of imprisonment with a fixed term for a single crime is 15 years. The gap between this sentence and life imprisonment and even the death penalty is great and needs to be restricted by means of clearer directions to courts.

It is easier to diagnose problems than to prescribe remedies. The great regional variation in ethnicity, religion, history and culture across China means that national sentencing guidelines may be harder to implement than in other, more homogeneous jurisdictions such as Minnesota, England and Wales, New Zealand or South Korea, all of which have adopted guidelines. From a long-term perspective, solutions to the challenges rely on systematic coordination among criminal law, judicial interpretations and sentencing guidelines. However, in the short-term, some lessons still can be drawn from the English experience.

\subsection{Monitoring and Evaluating the Guidelines}

The Coroners and Justice Act 2009 requires the English Council to monitor the operation and effect of the definitive guidelines. As a result of this duty, the Crown Court Sentencing Survey (CCSS) was launched in England and Wales to determine the level of judicial compliance with the guidelines. ${ }^{63}$ To date, neither the SPC nor the local judiciary in China have introduced a court-based survey of this kind. Therefore, no data are available to evaluate the compliance rate or the effects of the 2014 Guidelines on judicial practice. A national data collection exercise to establish levels of compliance with the guidelines is therefore an important priority. Without this step, it is impossible to monitor judicial compliance with the guidelines or to evaluate the impact of the guidelines on judicial behaviour. This is why the Sentencing Council for England and Wales created a bespoke survey that collects data directly from the sentencing authority - the court. Sentencing Commissions across the US achieve the same result by means of a "departure" report; this is a form completed by the judge every time a sentence imposed falls

${ }^{63}$ For a general introduction and the latest findings from the survey, see J.V. Roberts, 'Complying with Sentencing Guidelines: Latest Findings from the Crown Court Sentencing Survey', in A. Ashworth and J.V. Roberts (n 3 above). 
outside the guideline ranges. A database of sentencing decisions is necessary not only to permit an evaluation of the guidelines' effectiveness, but also to revise and amend the existing guidelines over time. Again, the experience in England and Wales is instructive. The Sentencing Council in that jurisdiction employs its survey of courts to revise existing guidelines as well as to determine sentence ranges for new guidelines.

\subsection{Conclusion}

China is the latest example of a jurisdiction seeking to impose structure on judicial discretion at sentencing. As such, the guidelines reflect, and build upon, developments elsewhere. These guidelines reflect a world-wide trend towards more structured sentencing. Very diverse legal regimes have introduced constraints upon the wide discretion that courts have typically enjoyed at sentencing. This evolution suggests a growing consensus that while discretion is necessary to ensure individualization, guidelines are also required to promote more principled and consistent sentencing.

The Chinese guidelines provide a systematic methodology to guide courts at sentencing, as well as comparatively detailed and prescriptive guidance regarding the consideration of important sentencing factors. To the extent that they are faithfully applied across courts, the guidelines are likely to have beneficial effects in terms of promoting more consistent and more principled sentencing. Moreover, in light of the importance, both regionally and globally of the Chinese state, the experience with this new approach to sentencing is likely to be emulated by other jurisdictions, particularly across Asia.

\section{OPEN ACCESS}

This article is distributed under the terms of the Creative Commons Attribution 4.0 International License (http://creativecommons.org/ licenses/by/4.0/), which permits unrestricted use, distribution, and reproduction in any medium, provided you give appropriate credit to the original author(s) and the source, provide a link to the Creative Commons license, and indicate if changes were made. 


\section{APPENDIX 1: THE 2014 CHINESE SENTENCING GUIDELINES ${ }^{64}$}

The following guidelines are drafted to structure sentencing discretion and implement the policy of combining criminal punishments with leniency in order to promote more open and fair sentencing.

\section{Guiding Principles for Sentencing}

1. Sentencing shall have facts as its basis and the law as its measure. The sentence shall be determined according to the facts of the offence, including the nature, circumstances and degree of social harm caused.

2. Sentencing shall reflect both the seriousness of the criminal act and the degree of the offender's culpability, such that the penalty is proportionate to the crime, and the goals of punishing and preventing crimes are achieved.

3. Sentencing shall reflect a policy of balancing leniency with severity to deliver lenient sentences when appropriate and severe when appropriate.

4. Sentencing should reflect variation in economic and social development as well as public security concerns in order to fulfill the aims of the criminal law. In cases that are comparable in terms of facts, region and timing, the sentences imposed shall be fundamentally proportionate.

\section{Sentencing Methodology}

Sentencing should be based on a qualitative analysis combined with quantitative analysis in order to determine the "Starting Point" sentence, the "Base" sentence and the "Declared" sentence.

\section{Sentencing Steps}

(1) The Starting Point sentence is determined within the relevant statutory penalty range on the basis of the facts constituting the crime;

(2) The "Base" sentence is determined by increasing the starting point sentence in light of other factors affecting the nature of a crime, such as the degree of harm, the number of counts and any other consequences of the crime;

\footnotetext{
${ }^{64}$ Note: translation by the authors, based on SPC Guiding Opinion on Sentencing of Common Crimes (2014), at: http://chinalawtranslate.com/en/spc-guidingopinion-on-sentencing-of-common-crimes-2014/.
} 
(3) The "declared sentence" is determined in accordance with law by adjusting the base sentence according to the sentencing circumstances and after considering all factors of the case as a whole.

\section{Procedure for Adjusting the Base Sentence}

(1) Where there is a single sentencing circumstance, directly adjust the base sentence accordingly.

(2) Where there are multiple sentencing circumstances, the base sentence is adjusted by weighing relevant aggravating and mitigating factors. Where there are sentencing circumstances such as a crime committed by a juvenile offender, an elderly offender, an offender who is mentally ill or with limited mental capacity, or a deaf-mute or blind offender; or for unjustified self-defense, excessive necessity, criminal preparation, an attempted crime, or an aborted crime; or where one is an accessory or accomplice under duress or an abettor; first use those sentencing circumstances to adjust the base sentence and use other sentencing circumstances to make subsequent adjustments to that base sentence.

(3) Where the defendant has committed a number of crimes and also has relevant sentencing circumstances such as meritorious contributions or repeat offences applicable to each offence, first, apply those sentencing circumstances to adjust each crime's base sentence and determine the penalty that should be given for each offence, then decide on the punishment to be imposed by combining the punishment for several offences in accordance with law.

\section{Determining the Declared Sentence}

(1) Where the result of adjusting the base sentence falls within the statutory range and is commensurate with the offender's culpability, it may be directly imposed as the declared sentence; if there are circumstances that should mitigate punishment, a declared sentence below the statutory minimum should be imposed.

(2) Where the result of adjusting the base sentence based on the sentencing circumstances results in a sentence below the statutory minimum penalty, there are circumstances that mitigate the punishment and the penalty is commensurate with culpability, it may be directly imposed as the declared sentence. Where there are only mitigating circumstances, the statutory minimum sen- 
tence may be determined as the declared sentence in accordance with law. However, based on the facts of a given case and upon review and approval from the Supreme Peoples' Court, a punishment below the statutory minimum may be imposed.

(3) Where the result of adjusting the base sentence based on the sentencing circumstances is above the statutory maximum, the imposed sentence may rise to the maximum statutory penalty in accordance with law.

(4) Considering all case circumstances, a sole judge or judicial panel may make adjustments to the base sentence within a range of $20 \%$ when determining the declared sentence. Where, after adjustment, the result still fails to meet the requirement of rendering the punishment proportionate to the crime, it should be referred to the adjudication committee for discussion and determination of a declared sentence in accordance with law.

(5) Where on comprehensive consideration of all case facts and circumstances, a punishment of life imprisonment or higher, supervised release, independent use of a supplementary punishment, a suspended sentence or waiver of punishment is imposed, it shall be applied in accordance with law.

\section{Application of Common Sentencing Factors}

At sentencing, all statutory and discretionary sentencing circumstances should be considered and the application for each sentencing factor lawfully determined on the basis the facts of the case and other relevant circumstances. When determining the sentence for offences that inflict serious harm (such as seriously violent crimes and drug crimes), the punishment shall be severe. When the crime is relatively minor, the punishment shall be lenient. When determining the adjustment for each relevant circumstance, the adjustment range and the actual increase or mitigation shall be balanced to ensure that the punishment is proportionate to the offender's degree of responsibility for the offence.

1. For juvenile crimes, the juvenile's capacity to understand the crime, motive for committing a crime, age at the time of the offence, whether they are a first or casual offender, expressions of repentance, personal experiences and demeanor shall be considered, and a lenient punishment imposed.

(1) For crimes committed by minors who are between 14 and 16 years of age, reduce the base sentence by $30-60 \%$; 
(2) For crimes committed by minors who have reached the age of 16 but are under the age of 18 years of age, reduce the base sentence by $10-50 \%$.

2. For inchoate offences, the courts shall consider circumstances such as the extent to which the crime was completed or inchoate, the extent of the harm caused and the reason why the crime was uncompleted. The base sentence may be reduced up to $50 \%$ of that imposed for the completed offence.

3. For accessories to a crime, their position and role in the common offence shall be considered along with whether or not they carried out the offence and other such relevant circumstances. This should result in a lenient punishment, reducing the base sentence by $20-50 \%$. Where the offence is minor, reduce the base sentence by $50 \%$ or more, or the punishment may be waived entirely.

4. For voluntary surrender, courts should consider the motive, timing and conditions of the surrender, the seriousness of the crime, the veracity of the offender's account of the offence, and any expression of remorse. Thereafter, the base sentence may be reduced by up to $40 \%$. Where the offence is minor, the base sentence may be reduced by more than $40 \%$ or the punishment waived entirely. This does not include misuse of the voluntary surrender provisions to avoid legal sanctions and other situations insufficient to justify lenient punishment.

5. For meritorious contributions to society, courts should consider the magnitude, content, motivation and effect of the meritorious contributions, as well as the seriousness of the offence in order to determine the extent of leniency.

(1) Where there is an ordinary meritorious contribution, the base sentence may be reduced by up to $20 \%$;

(2) Where there is an extraordinarily meritorious contribution, the base sentence may be reduced by $20-50 \%$, and where the crime is minor, reduce the base sentence by $50 \%$ or more, or waive punishment entirely.

6. For confessions, consider circumstances such as the stage when the offender truthfully disclosed the criminal conduct, the extent, the gravity of the crime and the degree to which they express repentance, in order to determine the degree of leniency.

(1) Where an offender honestly confesses his criminal acts, the base sentence may be reduced by up to $20 \%$; 
(2) Where an offender honestly confesses similar serious criminal acts that the justice system was unaware of, the base sentence may be reduced by $10-30 \%$;

(3) Where an especially serious consequence is avoided as a result of the offender's disclosure, the base sentence may be reduced by $30-50 \%$.

7. Where the crime is voluntarily admitted at court, the base sentence may be reduced by up to $10 \%$ on the basis of circumstances such as the nature of the crime, the seriousness of the crime, the extent of the confession and expressions of remorse. This does not include those verified as voluntary surrender or confessions.

8. For the return of unlawful gains or restitution, the base sentence may be reduced by up to $30 \%$ on consideration of the nature of the crime, the degree to which the return or restitution can offset the harm and the amount of restitution. Crimes of robbery and other crimes that seriously harm social order should be punished severely.

9. Where the victim's economic losses have been compensated and their forgiveness obtained, the base sentence may be reduced by up to $40 \%$ on consideration of the nature of the crime, the amount of compensation, the offender's ability to make compensation and the degree to which the crime is admitted and repented. Where there is active compensation but forgiveness is not forthcoming, the base sentence may be reduced by up to $30 \%$. Where forgiveness exists even though there was no compensation, the base sentence may be reduced by up to $20 \%$. Crimes that seriously threaten public security (such as robbery or rape) should be punished severely.

10. Where parties reach a settlement in accordance with Article 277 of the Criminal Procedure Law, the base sentence may be reduced by up to $50 \%$ on consideration of the nature of the crime, the amount of compensation, formal apologies and genuine repentance; where the crime is minor, the base punishment may be reduced by $50 \%$ or more or punishment may be waived entirely.

11. For repeat offences, the base punishment shall be increased by $10-40 \%$ on consideration of the nature of the previous and subsequent crimes, the length of the period of time between completing or being released from a previous punishment and the commission of a new crime, as well as the seriousness of the previous and subsequent crimes. 
12. For offenders with criminal records, courts shall consider circumstances such the nature of the prior convictions, the length of time since the previous convictions and the severity of the sentence imposed for the previous offences. The base sentence may be increased by up to $10 \%$. This does not include prior convictions for criminal negligence or juvenile crimes.

13. Where the victim of a crime is a minor, a senior, a disabled person, a pregnant woman or other vulnerable person, courts shall consider circumstances such as the nature of the offence and the seriousness of the offence and the base sentence may be increased by up to $20 \%$.

14. For crimes committed during major natural disasters or during the prevention and control of an infectious disease outbreak, the base sentence may be increased by up to $20 \%$, according to the specific circumstances of the case. 